\section{Role of procalcitonin in paediatric burin. wound sepsis}

To the Editor: Wound infection is a leading cause of mortality and morbidity in patients with burns. It can cause burn wound conversion, spread systemically, delay wound healing and lead to hypertrophic scars, and it increases mortality by 50 $60 \%$ despite improvements in antimicrobial management. Many factors contribute to the high incidence of burn wound infection, i.e. delayed initial care, deep burns, burns $>30 \%$ of the total body surface area, delayed wound closure and various host factors, such as malnutrition, comorbidities and immunosuppression. Other factors include the bioburden and virulence of the bacterial infection. The early diagnosis of burn sepsis is of crucial importance, as it reduces mortality and morbidity, and shortens antibiotic treatment and hospital stay. Furthermore, the unnecessary use of antibiotics has side-effects and can lead to antibiotic resistance, both of which are detrimental to the burn patient.

Burn wound infection remains a clinical and laboratory diagnosis and can be difficult to distinguish from the hyperdynamic, hypermetabolic status associated with burn injuries and systemic inflammatory response syndrome (SIRS). Because of the inflammatory response and immunoparesis associated with burns, standard laboratory tests for sepsis are difficult to interpret. ${ }^{[1]}$ As the clinical picture between SIRS and sepsis can overlap and blood culture yields are typically low, diagnostic predicaments are created that have implications for therapeutic choices.

In our paediatric burns unit, we have introduced specific measures to reduce the infection rate, detect burn sepsis early and differentiate SIRS from sepsis. Diagnostic uncertainty is common in the burns patient, despite careful physical examination, radiographs, tissue biopsies and various laboratory tests.

We introduced procalcitonin testing to assist with this diagnostic dilemma. Procalcitonin is a 116 amino acid protein and the precursor of calcitonin. It becomes detectable within 2 - 4 hours after a triggering inflammatory stimulus, peaking at 12 - 24 hours and remaining elevated for 24 hours. Procalcitonin secretion parallels the severity of the bacterial inflammatory insult, with higher levels associated with more severe disease and declining levels with resolution of illness. It does not increase in the case of viral or fungal burn infection. ${ }^{[2]}$
In our unit, patients are thoroughly washed from head to toe, including the burnt area. All loose skin is gently removed and hair is shaved where burns extend into the hairline. This has become an essential component of our initial care and should ideally be done within 8 hours after a burn. Furthermore, deep burns are excised and grafted early; measures are taken to promote primary wound healing and no prophylactic antibiotics are used. We distinguish SIRS from sepsis by using the American Burn
Association SIRS/sepsis criteria and we also view procalcitonin levels as a specific marker of bacterial sepsis (Fig. 1 and Table 1 ). ${ }^{[3]}$

In a recent study in our unit, sepsis was suspected in 74 infants; only 15 (20.3\%) had positive blood cultures. Procalcitonin levels in those with positive blood cultures were on average $39.4 \mathrm{ng} / \mathrm{mL}$ (95\% confidence interval (CI) 0.1 - 1303 ). All children survived. ${ }^{[4]}$ These results are supported by the meta-analysis by Cabral et al., ${ }^{[5]}$ who found procalcitonin to be $46.8 \mathrm{ng} / \mathrm{mL}(95 \%$ CI 2.5 - 91.1) in patients
Day post burn: ........

TBSA of burn: ..........

\section{Patient details}

\section{SIRS: $\geq 2$ of}

- Temperature $>38^{\circ} \mathrm{C}$ or $<36^{\circ} \mathrm{C}$

- Pulse (children $>2$ SD for age, bradycardia $<10$ th percentile)

- RR (children $>2$ SD for age)

-WCC (children leukocyte count elevated or depressed for age) or $>10 \%$ immature neutrophils

\section{SCORE: /4}

\section{SEPSIS: at least 3 of the following}

- Temperature $>39^{\circ} \mathrm{C}$ or $<36.5^{\circ} \mathrm{C}$

- Progressive tachycardia (children >2 SD)

- Progressive tachypnoea >30/min (children >2 SD)

- Refractory hypotension (children $<2$ SD for age)

- Leukocytosis $>12000$ cells/ $\mu \mathrm{L}$ or $<4000$ cells/ $\mu \mathrm{L}$

- Thrombocytopenia <100 000 (children <2 SD)

- Hyperglycaemia $>6.1 \mathrm{mmol} / \mathrm{L}$

- Inability to tolerate enteral feeds $>24$ hours

- Abdominal distention

- Residual volumes $>150 \mathrm{~mL} / \mathrm{h}$ children

- Diarrhoea $>400 \mathrm{~mL} /$ day

$$
\begin{aligned}
& \left(\ldots . . .{ }^{\circ} \mathrm{C}\right) \\
& \text { (......./min) } \\
& \text { (......./min) } \\
& \text { (............... mmHg) } \\
& \text { (....... cells } / \mu \mathrm{L} \text { ) } \\
& \text { (.......) } \\
& \text { (....... } \mathrm{mmol} / \mathrm{L})
\end{aligned}
$$

SCORE: /8

\section{INFECTION: at least one of the following}

- Positive culture or histology

- Strong suspicion of sepsis

- Retrospective response to antibiotics

\section{SCORE: $/ 7$}

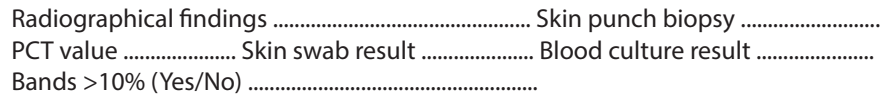

Comment: SIRS only Possibly septic Very likely septic

Decision of antibiotic usage: Yes/No

Choice of antibiotic

Fig. 1. Paediatric burns SIRS and sepsis log. $($ TBSA $=$ total body surface area; SIRS $=$ systemic inflammatory response syndrome; $S D=$ standard deviation; $R R=$ respiratory rate $/ \mathrm{min} ; W C C=$ white cell count; $P C T=$ procalcitonin.) 
Table 1. Paediatric values at 2 standard deviations of normal

\begin{tabular}{|c|c|c|c|c|c|}
\hline Age & $\begin{array}{l}\text { Tachycardia, } \\
\text { bpm }\end{array}$ & $\begin{array}{l}\text { Respiratory rate, } \\
\text { breaths/min }\end{array}$ & $\begin{array}{l}\text { Systolic blood } \\
\text { pressure, mmHg }\end{array}$ & $\begin{array}{l}\text { White cell count, } \\
\times 10^{9} / \mathrm{L}\end{array}$ & $\begin{array}{l}\text { Thrombocyte } \\
\text { count, } / \mu \mathrm{L}\end{array}$ \\
\hline 0 days - 1 week & $>180$ & $>50$ & $<65$ & $>34$ & $<150000$ \\
\hline \multirow[t]{2}{*}{$>1$ week - 1 month } & $>180$ & $>40$ & $<75$ & $>19.5$ & $<150000$ \\
\hline & & & & $<5$ & \\
\hline \multirow[t]{2}{*}{$>1$ month - 1 year } & $>180$ & $>34$ & $<94$ & $>17.5$ & $<150000$ \\
\hline & & & & $<5$ & \\
\hline \multirow[t]{2}{*}{$2-5$ years } & $>140$ & $>22$ & $<100$ & $>15.5$ & $<150000$ \\
\hline & & & & $<6$ & \\
\hline \multirow[t]{2}{*}{$6-12$ years } & $>130$ & $>18$ & $<105$ & $>13.5$ & $<150000$ \\
\hline & & & & $<4.5$ & \\
\hline \multirow[t]{2}{*}{13 - 17 years } & $>110$ & $>14$ & $<117$ & $>11$ & $<150000$ \\
\hline & & & & $<4.5$ & \\
\hline
\end{tabular}

with severe burn sepsis and $0.9 \mathrm{ng} / \mathrm{mL}(95 \% \mathrm{CI} 0.1$ - 1.6) in the noninfected group. A Taiwanese study by Wu et al. ${ }^{[6]}$ showed procalcitonin levels to be on average $47.19 \mathrm{ng} / \mathrm{mL}$ in burn patients with septic shock and positive blood cultures and $29.54 \mathrm{ng} / \mathrm{mL}$ in those with positive cultures without septic shock. In the culture-negative group, the average procalcitonin was $1.81 \mathrm{ng} / \mathrm{mL}$. Staphylococcal toxic shock syndromes typically give procalcitonin levels in the low hundreds and streptococcal toxic shock syndrome can give procalcitonin levels $\geq 1000 \mathrm{ng} / \mathrm{mL}$. Provided correct treatment is rendered, survival is excellent.

Our indication for testing procalcitonin would be a child who has confirmed SIRS and at least $3 / 8$ points, indicating sepsis on the American Burn Association SIRS/sepsis chart (Fig. 1). In the first 48 hours, children with signs of staphylococcal toxic shock syndrome (rash, fever, vomiting and diarrhoea) or ongoing tachycardia despite adequate pain control and resuscitation, would also be considered for testing. This is to identify toxic shock syndromes that occur in the first 72 hours. At a procalcitonin value of $>2 \mathrm{ng} / \mathrm{mL}$, we consider initiating intravenous antibiotics, although recent studies suggest that levels as low as $0.5-1.5 \mathrm{ng} / \mathrm{mL}$ may indicate sepsis. ${ }^{[-9]}$ Typically, blood cultures only become positive after hours or days, which delays appropriate goal-directed antibiotic therapy. Because of the half-life of procalcitonin (22 - 35 hours) and the cost of testing, re-testing should be performed after $48-72$ hours, unless the clinical picture indicates non-responsiveness to the chosen antibiotic. ${ }^{[8]}$ Antibiotic treatment may be discontinued with a procalcitonin value of $<2 \mathrm{ng} / \mathrm{mL}$ and if the clinical picture shows improvement.

Although testing is relatively costly (ZAR388.00 per test), we consider it to be cost-effective when taking into account the risk of delayed therapy, the cost of prolonged hospital stay and antibiotic treatment when not indicated, including that of intravenous cannulas, lines and fluids required to deliver antibiotic therapy.

In conclusion, procalcitonin testing is used in our burns unit as an early indicator of sepsis, toxic shock syndromes, monitoring response and stewardship to antimicrobial therapy.

\section{R Martinez, H Rode}

Department of Paediatric Surgery, Faculty of Health Sciences,

Red Cross War Memorial Children's Hospital and University of Cape Town, South Africa rouxmartinez@gmail.com

\footnotetext{
Jin M, Khan AI. Procalcitonin: Uses in the clinical laboratory for the diagnosis of sepsis. Lab Med 2010;42(3):173-177. https://doi.org/10.1309/LMQ2GRR4QLFKHCH9

Meisner M. Update on procalcitonin measurements. Ann Lab Med 2014;34(4):263-273. https://doi. org/10.3343/alm.2014.34.4.263

3. Hogan B, Wolf S, Hospenthal DR, et al. Correlation of American Burns Association Sepsis criteria with the presence of bacteremia in burned patients admitted to the intensive care unit. Retrospective chart review. J Burn Care Res 2012;33(3):371-378. https://doi.org/10.1097/BCR.0b013e3182331e87

4. Brink C, Isaacs Q, Scriba MF, Nathire MEH, Rode H, Martinez R. Infant burns: A single institution retrospective review. Burns 2018 (accepted for publication).
rent.

5. Cabral L, Afreixo V, Almeida L, et al. The use of procalcitonin (PCT) for diagnosis of sepsis in burn
Pastive 5. Cabral L, Afreixo V, Almeida L, et al. The use of procalcitonin (PCT) for diagnosis of sepsis in burn
patients: A meta-analysis. PLoS ONE 2016;11(12):e0168475. https://doi.org/10.1371/journal.pone. patients: A meta-analysis. PLoS ONE 2016;11(12):e0168475. https://doi.org/10.1371/journal.pone

6. Wu R, Chiu C, Lin T, et al. Procalcitonin as a diagnostic biomarker for septic shock and bloodstream infection in burn patients for the Formosa Fun Coast dust explosion. J Microbiol Immunol Infect 2017;50(6):872-878. https://doi.org/10.1016/j.jmii.2016.08.021

7. Mokline A, Garsallah L, Rahmani I, et al. Procalcitonin: A diagnostic and prognostic biomarker of sepsis in burned patients. Ann Burns Fire Disasters 2015;28(2):116-120.

Reinhart K, Karzai W, Meisner M. Procalcitonin as a marker of the systemic inflammatory response to infection. Intens Care Med 2000:26(9):1193-1200.

9. Kim H, Yang, H, Hur J, et al. Procalcitonin levels within 48 hours after burn injury as a prognostic factor. Ann Clin Lab Sci 2012:42(1):564
}

S Afr Med J 2018;108(10):793-794. DOI:10.7196/SAMJ.2018.v108i10.13515 